\title{
How Class Group Discussion and Positive Feedback Increases Student Engagement and Learning in International Postgraduate Students
}

\author{
DR. ANNA SEKHAR
}

\begin{abstract}
Substantiating the positive impact of both constructive feedback and class group discussions, observations done in one of the postgraduate management classes reveal some interesting facts that constitutes the core of this research. Although these informal observations were for one of the postgraduate units, this study could extend to both undergraduate and postgraduate classes. Findings over two trimesters authenticate how class group discussions and constructive feedback instill confidence to enhance student engagement and learning. This paper also expounds how such changes are profound when the class sizes were smaller although in both classes, the class participation and learning steadily increased from the start of the trimester through to the end indicating a positive correlation between feedback, student engagement and learning. Considering some of the challenges such as cultural shyness in international students, these constructive feedbacks and class group discussions seem to help them mitigate such inhibitions thereby enhancing their learning.
\end{abstract}

Keywords - class group discussion, communication, learning, student engagements.

\section{INTRODUCTION}

Before delving into this paper and the observations made, this research attempts to define the term feedback. When defined, feedback is the facilitators' response to a result or a process implemented by the student (1). Simply stated, from the viewpoint of a facilitator, a constructive feedback highlights those areas that a given student could improve and thus enhance their learning. Looking at the various types of feedback, research studies delineate that a constructive feedback could either be oral or written and appears institution specific. This said, in a holistic sense, with the entire process of giving feedback having undergone much transformation both in qualitative and quantitative terms, the overall nature of feedback seems summative with more focus on the grades than enhancing student engagement and learning. With the above, this paper aims to use the observation made to focus on the importance of constructive and positive feedback along with class group discussions to enhance both learning and student engagement. While on the one hand, the scope of this paper extends to other units at both undergraduate and postgraduate

DR. ANNA SEKHAR

Senior Lecturer, Torrens University Australia, Sydney, Australia level; on the other, stretching this research even further, a comparative study of how class group discussions enhance student engagement and learning in the management units across other universities in Australia is another area worth an explore.

\section{LITERATURE REVIEW}

Literature reviews from social-cognitive theory expounds how human behavior is completely conditioned and regulated. Psychological theories have thus far focused on learning through effects of one's actions (2). In its rudimentary form, learning happens when students perform actions and notice the effects of their actions. Observing the positive and negative outcomes from a course of action, the entire learning process begins. In academic literature, great emphasis exists on facilitators' need to provide effective and constructive written or oral feedback to enhance overall learning and learners' engagement (3). Learning from response outcomes signifies the modulation of responses automatically and unconsciously based on the consequences of their actions. In the case of performing activities, student form ideas about what leads to what, act on them, predict the possible outcomes; students' learn from the feedback given whether their learning is adequate or if any change in needed their overall learning (2). This describes the handy role of a constructive feedback

An in depth study about the genesis of the term feedback, its evolution delineates that feedback archetype in Oxford, and Cambridge Universities adopt a detailed and frequent model with weekly tests followed by the feedback from the respective facilitator / tutor (Gibbs and Simpson, 2009 as cited in (2)). This said, with an increasing number of students entering the universities, this effective model appears to have undergone transformation.

Viewing facilitators as drivers of feedback, many higher education institutions face criticisms surrounding inadequacies of feedback to students (4). There appears to be discussions surrounding how, here in Australia, the course experience survey completed by students across universities indicates a less satisfied lot of students with response to their assessments and corresponding feedback. Studies reveal that while some students found their units interesting, barely a half of them thought their facilitators to be enthusiastic. Some other interesting revelations were that those students who worked on 
their own without any engagement in class discussion with their peers seemed disinterested in any class activities indicating a need for a constructive feedback and facilitation of class engagement (5). Other similar views from various literature indicate that resource constraints in higher education clearly leaves an indelible impact on student experience, that in turn signal the need for effective feedback practices to enhance student engagement and learning (6). To annihilate some of these criticisms, understanding some prescribed ways for a constructive feedback is essential. While one approach suggests a positive feedback (7), the other method most effectively used is 'feedback sandwich' (8).

The term feedback sandwich implies a novel method where a negative feedback sits embedded between two positive feedbacks. As is apparent, this novel approach called feedback sandwich seems designed to protect the motivation and selfesteem of students. Recapitulating the inhibitions and shyness that surround international students, whilst offering a feedback sandwich, the facilitator wedges the deficits or areas to improve in between two positive pieces of information (8). This said, research also brings out that such models could elevate the position of the facilitator to an 'expert' and that of the learner to a 'passive recipient of information' which indicates that the learners are less likely to grasp the feedback given.

Given that learners are not only knowers and performers, they are also self-reactors who have that distinct capability to motivate, regulate and guide themselves (2). Thus, depending on the skill of the facilitator and learner, feedback appears to have that unique dyadic quality of either helping students towards improving their performance or damaging the entire learning process (8).

This said, it also appears evident that humans have that advanced capacity for observational learning, which plays a pivotal role in enhancement of skills and knowledge (2). Clearly, although there does not appear to be one size fits all in terms of feedback, overall, the very purpose is to enhance student learning through constructive feedback. An in depth research in this area also highlight a slow transformation in the assessment pattern of higher education from the traditional final examination style to a more continuous form of assessment that could provide for a continuous constructive feedback. This said, it may be worth recapitulating that there is no one size fits all or simply, there is no universal structure to the provision of feedback.

\section{FEEDBACK - Definition AND PURPOSE}

Looking into the broad definition of the term, feedback is all dialogue to support learning in both formal and informal situations (Askew and Lodge, 2000 as cited in Boud, D and Molloy, E. 2013, p.10). There are literature reviews to explain how feedbacks work productive when:

a) Students are involved in a dialogue about their learning which in turn raises questions and awareness about their quality performance b) Constructive feedback $\mathrm{s}$ assist students in their selfevaluation that in turn enhance the engagement in class discussions and provide learning.

Although at a higher education level, there are some prerequisite skills expected out of students, this said, these existing skills sans constructive feedback diminishes learning (4). With the focus on student engagement on the rise, there seem to be many initiatives that aim at enhancing student engagement and learning. In line with the above, the very purpose of this paper is to explain that with class group discussions and constructive feedback, some observations made for the purpose of this research reveals an interesting increase in student engagement and in class participation. Further, with small class sizes, observations showed that the duration of student engagement increased considerably, that in turn played a profound part in enhancing student learning and communication. This paper also proposes on extending such observations to other units at both undergraduate and postgraduate levels.

It is imminent that effective feedback appears to be instrumental for class participation and student engagement that then instills motivation, confidence and learning. With a capacity to scaffold learning, engaging students with effective feedback, helps mitigate elements such as cultural shyness and other inhibitions, which shadow the growth of international students. Laying great emphasis on student engagement and learning, this paper clarifies that from an instructional process, feedback helps fill the gap between the current level of understanding and the level of understanding that the students aim to achieve. Thus, feedback provides for the two main audiences namely the facilitator and the student. While facilitators use feedback to make decision surrounding diagnoses and remediation, students use feedback to monitor their gaps and strengths such that the grey areas could be improved (9). Thus from the above, it is best understood that a constructive and effective feedback primarily provides convincing answers to questions such as;

1) Where am I going- what are the goals?

2) How am I going - what is the level of progress made?

3) Where to next - what steps are required to progress further?

From the above, clearly, although one particular approach does not seem to exist, some guidelines for effective feedback includes:

1) Efforts from students to tackle challenges

2) Developing error-free skills that leads to a self-feedback process and a modicum of knowledge, clear grasp of the concepts (7).

It is therefore evident that the above modus operandi enhances student learning through effective strategies that help retain the required knowledge for employability and leadership. All of the above explains the constructive role of a positive feedback. This said literature reveals how in some occasions, strategies for constructive feedback are less productive (7). A less productive feedback instills 
disengagement and abandoning of goals (Bandura 1982; Mikulineer 1988; Steinberg 1996 as cited in Hattie and Timberely 2007, p.87) which again reverts to the importance of constructive feedback seeming mandatory to develop selfregulation and error detection skills.

\section{A. Successful feedback}

For a feedback to be successful, both facilitators and learners understand and value constructive feedback (10). Feedback becomes successful when learners know how to use feedback and when they are equally active in the feedback process. Thus, feedback becomes constructive only when students understand the intrinsic value of the feedback given and modulate their learning strategies to enhance their learning process holistically. In line with the observations made in this paper, being active in the overall feedback process appears to create opportunities to self-reflect their work along with others, encourage discussions with their peers that in turn help learners come out of their shyness and inhibitions. Vividly, a willing adoption and effective utilization of actions that produce positive outcomes seem imminent as against those unrewarding outcomes that become worth a discard. With a view to succeed, learners play a pivotal role in influencing their own motivation (2) which clearly signals the positive role of a constructive feedback besides discussions in class that foster learners' engagement and learning.

The above thus expounds the importance of learners' engagement to benefit from a constructive feedback. Studies bring out how for an effective feedback, clarity surrounding its purpose is quintessential. Some interesting arguments describe feedback to best identify the gap between what is understood and what is not, but that said, the effectiveness of feedback depends on the nature of the gap (6). While some learners have displayed immense interest and engagement to enhance their overall learning, some others have displayed poor engagement ranging from selective reading of feedback or sometimes no reading of feedback at all. There are yet other part of research that bring out a poor level of student commitment and engagement that reflects on poor performance of students overall (11).

\section{B. Student Engagement}

Attempting to give a succinct definition of this term, student engagement implies students' active participate in learning activities. To have a successful student engagement, studies reveal that a student must necessarily possess:

- A goal or a reference that he/she should aim for

- Compare the current performance with the standard

- Engage in the possible action that can help fill the gap and achieve the goal (9)

Attempting to answer the question as to how well do learners engage in practice, this leads to another question on how to nurture stronger engagement such that learners become proactive receivers and seekers of constructive feedback. Involving the learners in the overall feedback process reflects a transformation in learners' from being passive to more active receivers and seekers of feedback (3).

In general, studies reveal that student engagement revolves around student satisfaction and equality of student experience besides curriculum design that is not an object of focus in this research. Imminently, feedback plays an important role in the overall learning process and continues to be a subject of ongoing discussion. Given the complex nature of feedback, while on the one side, claims point to learners as best judges of an effective feedback, the other side analyses if learners recognize its benefits. As a careful analysis, this research lays its importance on constructive feedback and student engagement through class group discussions and alongside, highlights the constrained nature of feedback owing to paucity of time for facilitators. Whilst talking about effectiveness of feedbacks, this paper also makes a brief mention that clarity of its purpose makes feedback more effective (6). With hurdles surrounding positive feedback, an amicable and amiable way of solving the problem could mean a better understanding of what feedback is from both facilitators' and students' view.

\section{Class GRoup Discussion AND InCREASED STUDENT ENGAGEMENT}

There exists many arguments that favor active learning through active participation in class discussion. There are many questions existing surrounding how to engage students effectively using a constructive feedback. Some studies interestingly reveal that engagement in class is not solely the responsibility of the student, but that said it is that interaction between learners and facilitators that constitute engagement. Although findings from one of the studies done on student and staff effectiveness of feedback point out that students were generally critical of the feedback received and claimed they found it difficult to adjust their approach in line with the feedback received (6).

It seem apparent that along with class group discussions and constructive feedback from the facilitators and peers, a healthy student engagement seem to prevail besides confidence, motivation accompanied by healthy argumentative discussion amongst students. A deeper understanding of student engagement reveals that enhanced participation in class group discussions seem to strengthen students' understanding of the concepts covered by the facilitator during lectures besides a better capacity to retain the acquired information.

To substantiate this, this paper discusses the observations made on a large group of students in one of the management units at the postgraduate level. To fathom the whole idea, an information observation done by the author on three separate group of students over two trimesters has some interesting revelations. In both the trimesters, results lean towards a positive correlation between class group discussion, student engagement and learning. Irrespective of the class size, these results shown the same outcome. This said, out of the three class groups chosen for this observation, two had a medium to large class groups of up to 35 students and the other a smaller number of students of up to 11 students. 
The above theoretical description stands best explained using the following graphical representations. Giving a bit of an insight into the diagrams shown below, graph 1 displays a steady increase in student engagement by the students in one of the management units at the postgraduate level in Trimester 2,2019 . While the number of students ranging from 1 to 35 is shown on the horizontal axis, weeks ranging from week1 through to week 11 is shown on the vertical axis. The blue bars in the graph indicate increasing student engagement on weekly basis in class group discussions. While some were actively involved in engagement from the start, the involvement of other students came from motivation by their peers besides constructive feedback from the facilitator.

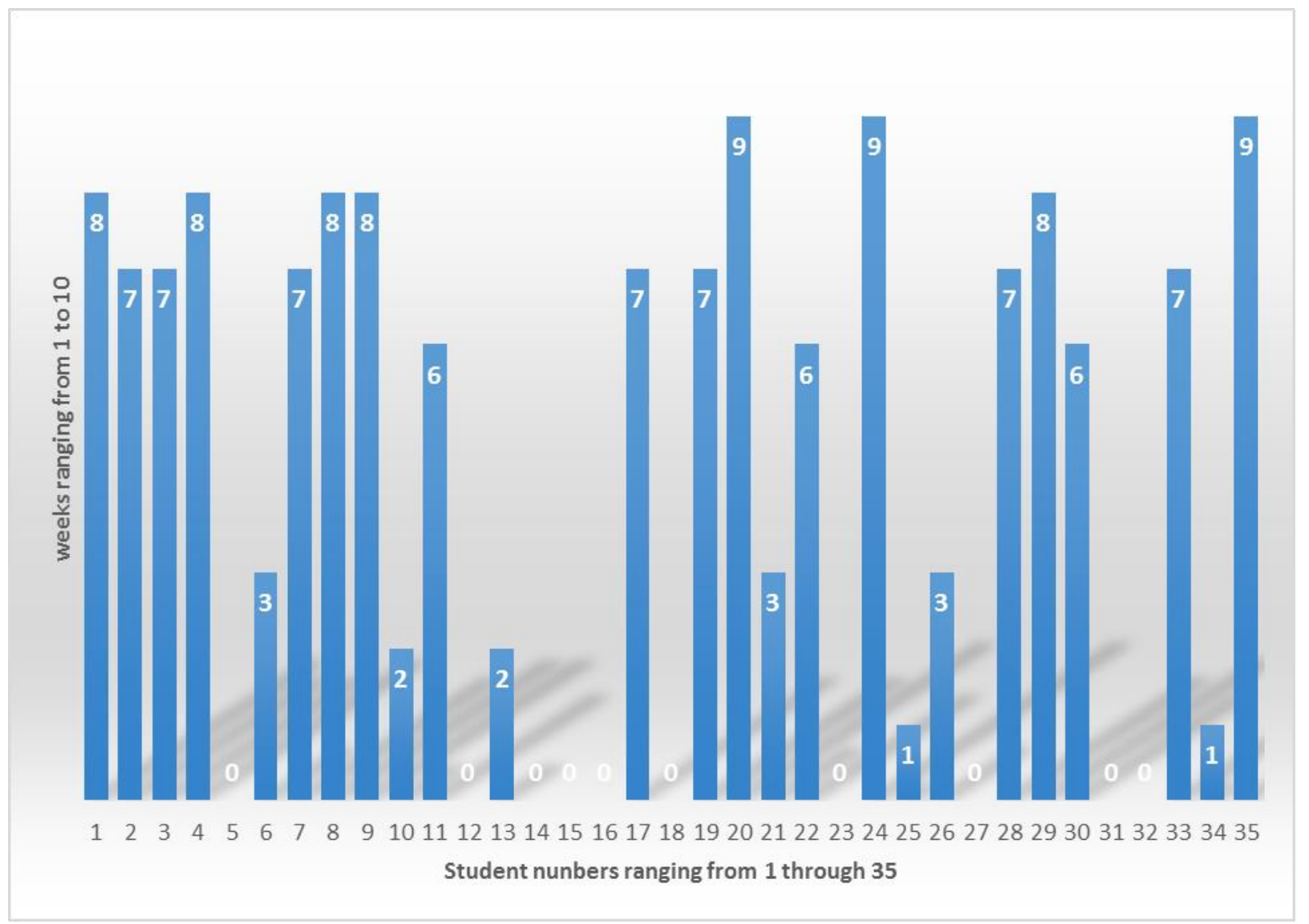

Fig 1: Graph 1: Participation in class discussion and student engagement - a positive correlation Trimester 2, 2019

At the outset, maintaining privacy and confidentiality of student information is the primary focus of this paper. As earlier mentioned, this diagram uses student numbers on the horizontal axis and week numbers on the vertical axis. The graph shown above displays a clear positive correlation between student engagement and learning on the one hand and class group discussion, constructive feedback on the other. Delving in further into the diagram, this observation done in the last trimester was the first ever-informal observation on students in one of the management units at the postgraduate level. Evidently, student engagement shows a steady increase from the earlier weeks of the term through to the end of the trimester.

The second graphical representation shows a similar observation for students in the same management unit at the Masters' level. However, this time, the informal observation conducted in the current trimester has two different class groups with different class numbers. 


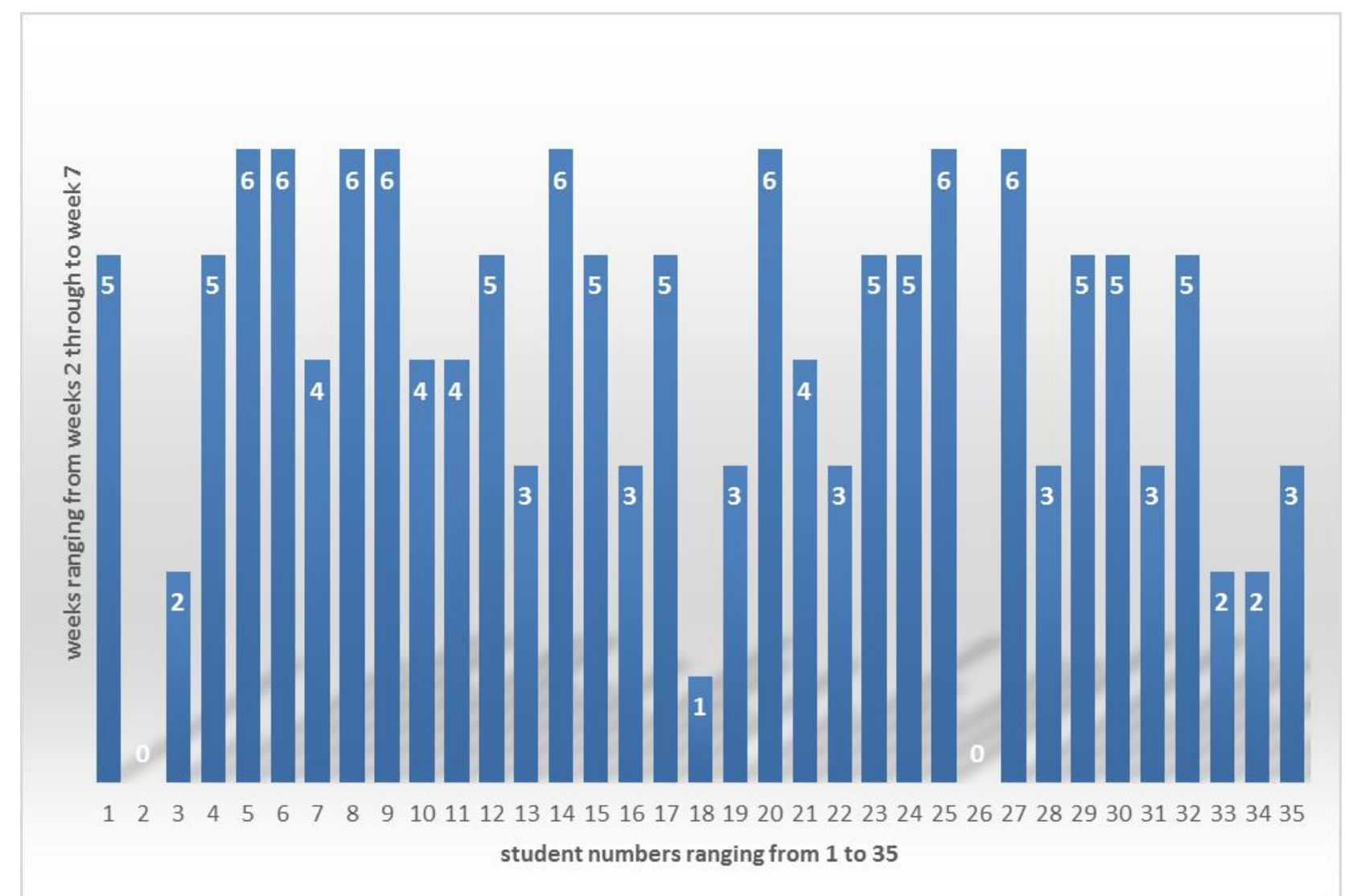

Fig 2: Graph 2A: Class participation and student engagement - a positive correlation in large class size in Trimester 3, 2019

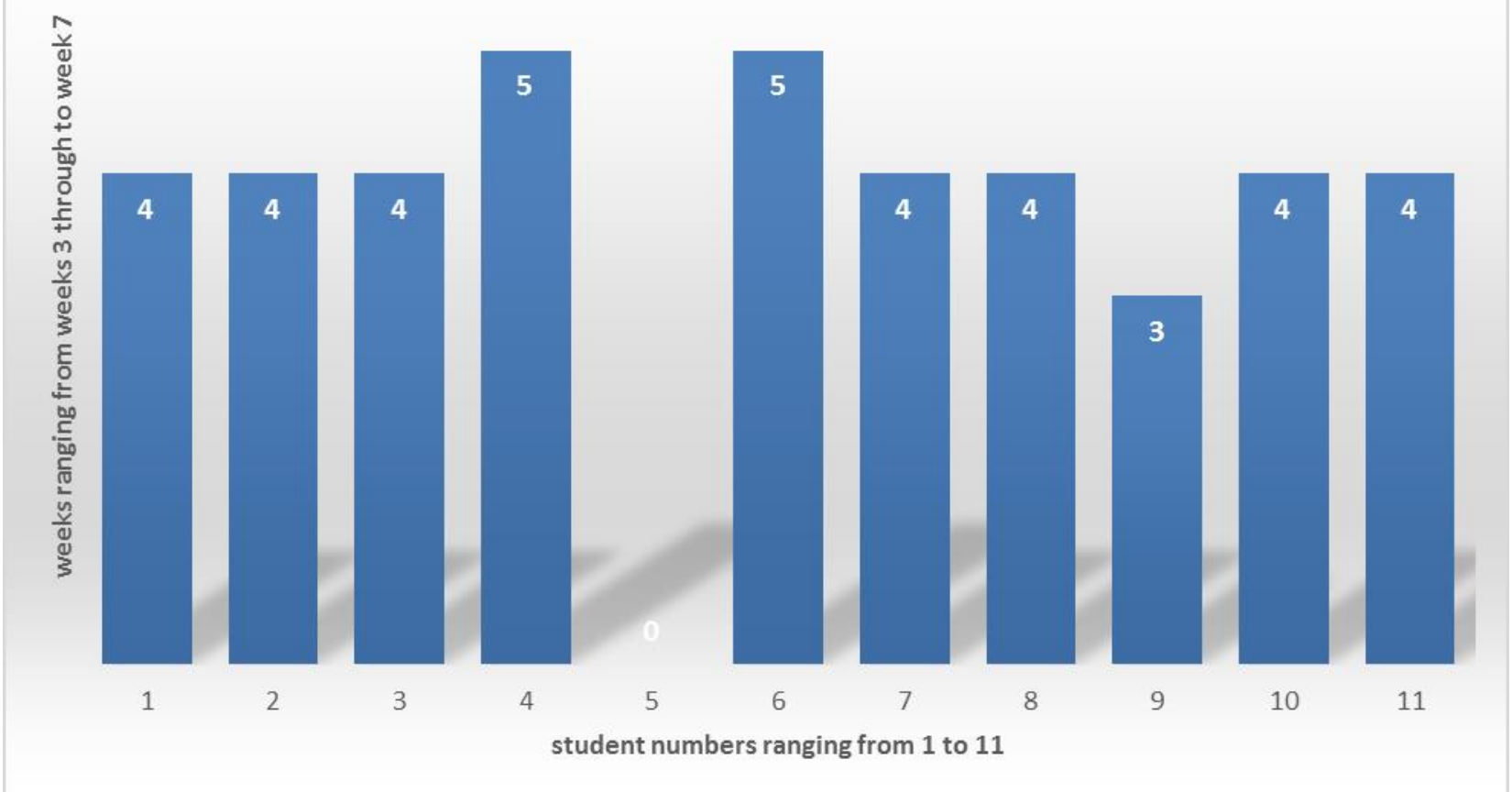

Graph 2B: Class participation and student engagement - a positive correlation in small class size, Trimester 3, 2019

When the class sizes are smaller, the duration of student

Some interesting revelations worth a mention are surrounding class sizes and its impact on student engagement. engagement in class group discussions seem longer and more profound than what would be the case in a class of 
approximately 35 students. With the level of confidence looking comparably better in small class sizes, students appeared to be at ease when amidst a healthy argumentative discussion with their peers. Constructive feedback from the facilitator accompanied by peer to peer feedback during class group discussions seem to play a deft role in minimizing inhibitions, shyness in particular amongst international students. The impact of feedback appeared more profound in small class sizes.

Alongside the above class observations, a theoretical discussion makes it apparent that:

There is increased student engagement when we create that atmosphere for class participation in the group discussion and ensure students contribute healthily towards the same.

There is a confirmation of learning through verbal and nonverbal cues such as effective integration of concepts covered in the group discussion process.

There is deepening of understanding as viewed by some students (12). Studies by the same set of authors expound that although class group discussion evidently increases student engagement and enhances learning, this said, indications also point towards the importance of constructive feedback from all nodes of study such as peers and facilitators.

It is evident that feedback from these diverse sources instills that much needed confidence, communication skill and motivation all of which contribute towards increasing employability (12). Some students who listened to the conversations and discussions seemed steadily motivated to participate in class group discussions that enhanced their grasp of concepts covered in class and helped them retain that acquired information much better. The above theory appears described adequately in the graphical representations shown above. With every week that went by, the number of students participating in class group discussions were on the rise; peerto-peer feedback also meant new students showing their willingness and enthusiasm to engage in discussions, display a better understanding of the concepts and enhance the learning process holistically.

\section{CONCLUSION AND SCOPE OF THIS PAPER}

In conclusion, it is evident that a holistic and a sociallyembedded conceptualization of feedback and engagement seems essential such that the conceptualization could assist facilitators in encouraging learners to develop their engagement and enhance their overall learning rather than merely responding to facilitators instructions as passive recipients of feedback (13).

Although observations reveal feedback to be a wholesome experience, where learners make sense of their information relating to their performance and learning strategies, it is thus far not free from challenges. Criticisms do exist that while a lot of time gets devoted towards provision of feedback, its effectiveness gains less significance (6). Some of the core challenges discussed for a better analysis of the chosen area of research are (4):
1) Process: there is no universal approach to feedback that is a one size fits all for all learners universally

2) Information: similar to the above, it seems challenging at times to provide information that may be a universal fit for all the students and learners. Ultimately, a successful feedback also centres on what sort of information could benefit learners and facilitate their increased engagement in class discussions besides enhance their overall learning.

3) Impact: studies expound that challenge should allow learners to show the impact of the constructive feedback on their learning and engagement

4) Performance: Feedback does not end clearly with a simple description that learners should make sense of the information given. It is apparent that feedback should also provide a transparent and clear idea about when, how and what performance needs periodic assessment

5) Quality: It would be highly helpful if the feedback information clearly relates to some kind of a high benchmark that could enhance the quality of learning overall

From the above, it is imminent that this working paper, at this moment has focused its observation on just a management unit at the postgraduate level. This said, as a part of future research, study could extend to other units at both undergraduate and postgraduate levels. Besides, this research also aims to explore how constructive feedback coupled with class discussion activities enhances student engagement and learning in particular with international studies in other universities across Australia. By this, this working paper seeks to make a comparative study of best practices that could overall increase student participation and learning at both undergraduate and postgraduate levels.

\section{ACKNOWLEDGMENT}

I would sincerely like to thank my colleague Dr. Arezou PourMirza for sharing her idea surrounding observing students' preparedness with their reading modules for the weekly lectures. I have modified the idea to suit my management subject as this is more of a soft skill unit where student engagement in class is paramount.

\section{REFERENCES}

[1] M.J. Garcia-Sanpedro, Feedback and Feedforward: Focal Points for Improving Academic Performance. Journal of Technology and Science Educatiom, 2012.

https://doi.org/10.3926/jotse.49

[2] Bandura, A. Social Cognitive Theory: An agentic approach., Asian Journal of Social Psychology, 1999, pp. 21-41. https://doi.org/10.1111/1467-839X.00024

[3] Winstone, N, E, et al. Supporting Lerners' Agentic Engagementwith Feedback: A Systematic Review and a Taxonomy of Recipience Processes. 1, s.l. : Routledge Taylor and Francis Group, Educational Psychology, Vol. 52, 2017, pp. 17-37. https://doi.org/10.1080/00461520.2016.1207538

[4] Boud, D and Molloy, E. Rethinking Models of Feedback for Learning: The challenges of design. 6, Assessment and Evaluation in Higher Education, Vol. 38, 2013, pp. 698-712.

https://doi.org/10.1080/02602938.2012.691462 
[5] Krause, K., et al. The First year experience in Australian Universities: Findings from a Decade of National Studies. Melbourne : Department of Education, Science and Training, Australian Government, 2005.

[6] Price, M., Handley, K. and Millar, J. Feedback: All that effort, but what is the effect? 3, s.l. : Routledge- Taylor \& Francis, Assessment \& Evaluation in Higher Education, Vol. 35, May 2010, pp. 277-289. https://doi.org/10.1080/02602930903541007

[7] Hattie, J and Timperley, H. 1, The Power of Feedback., Review of Educational Research, Vol. 77, March 2007, pp. 81-112. https://doi.org/10.3102/003465430298487

[8] Molloy, E.K. The Feedforward Mechanism: a way forward in clinical learning? 2010, Medical Education. https://doi.org/10.1111/j.1365-2923.2010.03868.x

[9] Sadler, R. Formative assessment and the design of instructional system,. Instructional Science, 1989, pp. 119-144. https://doi.org/10.1007/BF00117714

[10] Henderson, M, et al. Feedback for Learning - Closing the Assessment Loop. feedbackforlearning.org. [Online] n.d.

[11] Steinberg, L. Beyond the Classroom: Why School Reform Has Failed and What Parents Need To Do. New York, 1996. p. 223.

[12] Dallimore, E.J, Hertenstein, J.H and Platt, M. B. How do students learn from participation in class discussion? Faculty Focus | Higher Ed Teaching \& Learning . [Online] 27 March 2017. https://www.facultyfocus.com.

[13] Price, M, Handley, K and Millar, J. Feedback: Focussing attention on engagement, Studies in Higher Education, Vol 36(8). : Taylor \& Francis Online, 2011, Studies in Higher Education, Vol. 36, pp. 879-896, doi: 10.1989/03075079.2010.483513. 